\title{
Information as "Commons": Applying Design Principles to ICTD Projects
}

\author{
V.L.V. Kameswari \\ G.B. Pant University of Agriculture and Technology \\ Pantnagar, Uttarakhand, India \\ vlvkameswari@yahoo.co.in
}

\begin{abstract}
Information is considered as a prerequisite for development in today's world. This belief has led to several measures to make information freely available to the citizens. Use of ICTs for development is a step in that direction, as they are expected to make communication more democratic and easy, leading to developmental outcomes. It is estimated that $60 \%$ of all ICT projects in Asia are located in India. Many players - national and state governments, private business organizations and civil society groups are engaged in their implementation. Despite huge investments, studies indicate that the developmental use of such projects is very low. ICTs for development projects have been studied using diverse tools and theories. Failure has been attributed to several factors including various types of barriers, faulty institutions, and technology related issues. This paper places analysis on ICTD projects within the context of CPR (Common Pool Resources) studies. In recent years, the definition of CPR has been expanded to include information as "new commons" and robust institutions are deemed essential for survival of all CPRs. In this paper, ICT based development projects have been interpreted as CPR institutions and CPR design principles have been used to explain the functioning of two ICTD projects. Both these studies were carried out in the state of Uttarakahnd, India and analysis is confined to use of agricultural information by the farming community.
\end{abstract}

Keywords: Information commons, Design principles, ICT projects.

\section{Introduction}

Information is posited as the prime mover of development in today's world. Hence, terms like knowledge society, knowledge economy, information movement, etc are in wide currency. There is a growing conviction that the future growth of nations will be limited less by financial/ capital resources in the years to come. It is oft repeated statement that countries will fail in their quest for development due to their inability to produce, process and use information. This belief is underlined by the growing number of ICT (Information and Communication Technology) projects, especially in the developing world. According to Yunus (2006), ICT is transforming the world into a distanceless, borderless world of instantaneous communication and access to ICTs can change the lives of poor people. The mushrooming number of ICT based development projects in India can be seen as a testimony to this view. 
According to the World Resources Institute, India accounts for $60 \%$ of the ICT projects in Asia. The idea behind most of these initiatives is to democratise information and make it more easily available to the citizens with a hope that access to information will have developmental outcomes. However, studies on the impact of such projects indicate low usage for development purpose (Kiri and Menon, 2006; Veeraraghavan et al, 2006; Toyoma, 2010).

ICTs for development projects are institutions developed for governing the use of information, which is a Common Pool Resource (CPR). This paper analyzes two ICTD projects (Janadhar and IFFCO Airtel Green Card) using CPR design principles put forth by Ostrom (1990). Low usage by the intended users (farmers in these cases) has been traced to absence of most of the design principles deemed essential for the survival of long enduring CPR institutions. The scope of both the studies was limited to use of agricultural information by the farming community through these projects.

The study on Janadhar project was taken up to develop a profile of users of "Rural Knowledge Centres" and their perception about these Centres vis-à-vis traditional extension system (Barala, 2006). On the other hand, the study on IFFCO Airtel Green Card was designed to understand the factors affecting use of mobile phones by farmers for seeking agricultural information and their relationship with the socioeconomic status of the respondents. In both cases, in-depth interview schedules were used for data collection. Sample size comprised of 152 farmers in the first study and 277 (out of which only 70 were primarily engaged in agriculture) in the second instance. In the case of IFFCO Airtel Green Card study, respondents were scattered over a large geographical area. Hence, interview schedule was administered through telephonic as well as face to face interviews. Socio-economic status of the farmers and subsequent classification into low, medium and high categories in this study was done using standardised scale developed for rural population in India $(r=0.93)$. The scale comprises of nine items. After an in depth review of literature and consultation with experts, five factors; viz; ease of use, message comprehension, usefulness of information, trustworthiness and cost were selected for the study. The effect of these factors on the use of mobile phone by the farmers and their relationship with the socio-economic status of the users was analyzed using $\chi 2$-test at $5 \%$ level of significance (Sahota, 2009).

Rest of this paper is divided into six sections. Section two elaborates the concept of Common Pool Resources and evolution of the term to include information as "commons". Third section discusses the characteristics of institutions that govern long enduring CPRs. Section four briefly describes the ICTD projects analysed in this paper and section five applies CPR design principles to these projects. Sixth section briefly discusses ways of incorporating CPR design principles in ICTD projects and concluding remarks constitute the last section of the paper.

\section{Common Property Resources and the "New Commons"}

The term Common Pool Resource (CPR) has been used with diverse connotations to represent a wide variety of resources by scholars from various disciplines. While most of the work on common pool resources has been attributed to economists, CPR literature is replete with contributions from historians, political scientists, anthropologists, 
sociologists, ecologist and others. At an elementary level, Common Pool Resources (CPR) or simply "commons" are resources that are shared by a group of people and are subject to social dilemmas. However, much of traditional CPR studies use two biophysical attributes: non excludability and non rivalrous consumption to delineate CPRs from other types of goods. As per this classification, in case of CPRs, it is difficult to develop institutional or physical means to exclude beneficiaries or users and consumption of the resource by one person limits or subtracts from the quantity available to others. Hence, the term is commonly defined as "a natural or man-made resource from which it is difficult to exclude or limit users once the resource is provided by nature or produced by humans" (Ostrom, 1990). The "commons", however, are different from public and private goods while sharing some of their characteristics. Like public goods, they can be used by a number of people. But, their use by an individual who appropriates a portion of the resource makes it unavailable to others (Oakerson, 1990). De Moore (2011), however, argues that two more characteristics which were inherent to historical "commons"; viz; institutionalisation and self governance, need to be included while defining a Common Pool Resource. Though the term itself is often confused with a type of property right, Ostrom (1994) succinctly points out that CPRs can be owned by national, regional or local governments, communities, individuals or may even be used as an open access resource. In other words, a common pool resource may not always be governed through a common property regime.

According to Hess (2000) most of the initial literature on CPRs was concerned with the use and governance of natural resources and included such broad categories as agriculture, fisheries, grazing and forest land, water bodies, wild life, etc. In an indepth analysis of CPR literature, the author notes that the scope was widened towards early 1990s to include technology driven human made resources. Non traditional CPR studies included analysis of apartments, streets, highways, parking places, etc. which were grouped as "new commons". The term was soon expanded to include "global commons" such as radio spectrum, atmosphere, high seas, polar regions, etc. which have "remained unclaimed due to lack of technology for extracting their value and for establishing and sustaining property rights".

Information is a fuzzy term and has been used in several ways. One way of reducing this confusion is by using the distinction between data-information-knowledge. Data is viewed as information in raw form, information is defined as organized data in a context, and knowledge as the assimilation of the information and understanding of how to use it (Machlup, 1983). While there is a definite distinction between information and knowledge, for the purpose of this paper the terms have been used interchangeably.

A resource is a good that can be transformed to produce a benefit which fulfils a need or want. It has utility, limited availability and faces depletion. People use information as a resource. They covet it, collect it and try to deny access to other using rules or technology. Massive amount of shared information made possible due to digital technologies (especially internet) coupled with infusion of scholarly works from other disciplines has given rise to studies that place information in the realm of "new commons". Broadly speaking, these studies examine both physical facilities (eg; digital libraries) and digital information (eg. open access journals) as "commons". The notion that information in the present age can be treated as "commons" and analysed as such is a contested issue. Hofmolk (2010) argues that "internet goods do not fall 
within the common pool category of goods". Such reservation in categorising information as "commons" is understandable in light of the key characteristics used to identity CPRs.

Prior to the digital age and advent of Information and Communication Technologies (ICTs), information was either a private good (due to limited individual ownership of scholarly works) or a club good (available in libraries, etc. whose membership was limited to some extent). Some may argue that opening of public libraries and other venues of storing scholarly works democratised information and turned it into a public good. However, conditions for access to such facilities and their limited number did not entail unlimited access and sharing of information, a key feature of public good. While it is difficult to exclude other users in case of information available through digital technologies (anyone with a computer and internet connection can access a wide range of information free of cost), information as "commons" does not meet the other key characteristic of CPRs i.e subtractability. As pointed out earlier, in case of traditional CPRs, use of a resource unit by one person limits or makes it unavailable to others. But, information as such is not divisible into subtractable resource units. In other words, access or use of information by one person does not make it unavailable to others. In fact, it may just be the opposite in some cases, where greater use leads to more value (eg; number of citations of a scholarly article). Information, therefore, has the attribute of non excludability but not subtractability. However, in rare cases, issues related to network congestion, limited number of terminals, band width restrictions, etc. may make information "commons" both excludable and subtractable.

With CPR literature gaining maturity and depth, it was realised that the distinction between various goods based on excludability and non rivalrous consumption is not as clear cut as it may seem in the first instance. Goods which were previously thought of or placed under one category may shift due to change in environment (e.g. air), technology (e.g radio spectrum) or legal measures (high seas). Hence, it is more useful to see both the key attributes of CPRs as a continuum rather than as dichotomous categories and some goods may fall and/ or shift in between the two extremes (De Moore, 2011).

Nevertheless, the general consensus is that information in the digital age is a Common Pool Resource, for which exclusion of beneficiaries is difficult, costly, or technically infeasible, and in which exploitation by one user may limit availability of the resource or reduces its value to others to some extent. Information is also vulnerable to classic CPR dilemmas like free-riding: either through overuse (dumping of irrelevant and redundant information, mingling of unreliable and high quality information making it difficult for the users to put it to use) or as a result of inadequate investment and maintenance necessary to sustain and enhance the physical facility (Bernbom, 2000).

In CPR literature, the term "information" commons is used synonymously with or confused with "knowledge" and "internet" commons. This confusion has been addressed in several ways. Bernbom (2000) labels internet as a global collection of multiple, interrelated resource facilities and contends that each one may be analyzed as a Common Pool Resource (CPR). Internet is viewed as an amalgam of three types of commons; viz; network commons (physical network infrastructure), information 
commons (vast and distributed collection of information resources that is available through use of physical infrastructure), and social commons (global communications forum). Internet commons has also been analysed as a composite good with three distinct layers; viz; physical (mainly comprising of equipment), logical (underlying code), and content (the message) (Benkler, 2002).

Common Pool Resource studies (especially those concerned with composite/multiple CPRs) differentiate between resource system and resource units. A resource system holds the resource unit and is usually not owned by an individual. On the other hand, resource units are individual transferable goods that can be put to use/ exploited by each user. Hess and Ostrom (2001) note that while trying to extend the evolving theory of common-pool resources to "new commons", especially information and the intellectual public domain, this distinction can be modified into a threeway division between the artifact, the facility, and the content. An artifact is "a discreet, observable, nameable representation of an idea or set of ideas". Articles, books, database, etc are typical examples of artifacts. While physical artifacts are used in a sequential manner by multiple readers, digital artifacts can be used simultaneously by several users. On the other hand, a facility is a storehouse of artifacts. They can be compared to the resource system in conventional CPR theory and are subject to deterioration. They are usually governed by rules and norms and have a physical limitation on the number and type of artifacts that can be stored. Internet is a digital facility. Finally, "the content of an artifact in a facility is information......... and is the nonphysical flow unit". For the purpose of this paper, only content is being interpreted as a Common Pool Resource.

\section{ICTD Initiatives as Institutions for Information "Commons"}

"Most works written to-date studying the Internet as a common-pool resource centre on the technology infrastructure and the social network issues rather than the institutions developed about the distributed information per se" (Hess and Ostrom, 2001). Governance arrangements are extremely important for provision, production, appropriation, and use of long enduring CPRs as they are subject to free riding, resource degradation and competing users. Oakerson (1990) put forth a conceptual framework that can be used to analyse "commons" across a wide variety of resources and facilities. The framework has four sets of variables; viz, physical attributes, decision making arrangements, patterns of interaction and outcomes. These four variables can be used to describe any "commons" and each one of these is further subdivided into precise and measurable items.

The Institutional Analysis and Development (IAD) Framework (Oakerson, 1990) analyzes the physical attributes of the "commons" to decide on the scope, nature and boundaries of the resource. The physical attributes of the resource effect and are in turn influenced by the decision making arrangements, which are primarily concerned with governance issues (rules, etc.). Patterns of interaction refer to peoples' behaviour under established rules and physical constraints. People not only interact among themselves, but patterns of interaction may lead to compliance, donation or free riding of the resource. According to this framework, both physical attributes and patterns of interaction influence the final outcome or result. The framework can, however, be 
modified to gain a better understanding of institutional change. Outcomes can have a learning affect and thereby influence patterns of interaction, which in turn may lead to modified strategies. In the long run, decision making arrangements and technology can also be changed (thereby changing the physical attribute of the resource) to prevent destruction of the resourced or to get better outcomes.

Some of the attributes and their sub-components in the IAD framework are overlapping with CPR design principles developed by Ostrom (1990). Following an analysis of case studies involving a variety of CPRs, she developed eight design principles that characterise institutions governing long-enduring CPRs. She defines a design principle as “.... conception used either consciously or unconsciously by those constituting and reconstituting a continuing association of individuals about a general organising principle" and goes on to add that specific rules-in-use show a wide variation. These design principles include: (1) clearly defined boundaries which authorise individual users with rights to withdraw the resource units and clear cut boundaries for the CPR, (2) congruence between appropriation and provision rules and local conditions that ensure preservation of the resource, (3) collective choice arrangements that enable most resource users to participate in crafting rules, (4) monitoring resource condition and user behaviour, (5) graduated sanctions which are applicable to all violators of rules, (6) conflict resolution mechanism that is low cost and local, (7) minimal recognition of rights to organize that give some authority to users without undue interference, and (8) nested enterprises through which appropriation, provision, monitoring, enforcement, conflict resolution and governance activities are organised at multiple layers. These design principles have stood the test of time, have been widely used for analysing CPRs across the globe (especially natural CPRs) and have since acquired a prescriptive status. Only the initial seven design principles have been used for present discussion as the eighth principle (nested enterprises) applies mostly to larger and more complex CPRs.

\section{Brief Description of Projects}

Use of ICTs for development including agricultural growth started in India in late 1990s. Many players - national and state governments, private business organizations and civil society groups are engaged in their implementation and provide a wide variety of information ranging from government schemes, market information, technical advice and capacity building. Both the projects described below provide a variety of information that can be used by farmers.

Janadhar: Janadhar is an internet based e-governance initiative of the Government of Uttarakhand (a state in Northern India). It was started mainly to deliver information of public interest and services related to various government departments at the doorsteps of the citizens and also provide agriculture information to the farmers of the state. The project was started in March 2005 with funding from the United Nations Development Programme (UNDP) and technical guidance was provided by Indian Institute of Technology (IIT), Roorkee. The project was implemented through Rural Information Centres (popularly known as Soochna Kutir). These Rural Information Centres were managed by local youth who were trained in both organizational and technical 
aspect. At these Centres, information was provided to the citizens through a portal UTTARA - especially developed for the project by IIT, Roorkee. UTTARA contains a wide variety of information on the state and is a centralized "databank". The portal is hosted on a group of servers located in the data centre at IIT, Roorkee. Information is predominantly in Hindi (local language), while a few pages are in English and the homepage and information of more general interest is in both Hindi and English.

Janadhar highlights a case where more than one type of property regime is in place. The project itself (hence the portal) was owned by the Government of Uttarakahnd, through IIT, Roorkee. But, the Rural Information Centres were essentially a private property as the service delivery was handed over/ contracted to individuals who were responsible for establishing and running the Soochna Kutir as a self employment venture. Hardware and internet connectivity was provided by IIT, Roorkee and the owner (who also acted as an infomediary) provided physical space for the Centre. It was found that only $10 \%$ of the sampled population had used the services offered under the project since its inception (Barala, 2006).

There are several reasons for low usage by the farmers. Firstly, the infomediaries (Sanchalak), who were also owners of the Rural Information Centres, did not find these centres economically viable and attempted to augment their income by providing market driven services like public telephony, DTP work, coaching classes, internet browsing, etc. This resulted in dilution of services offered by the project. Secondly, in most cases, the Centres were contracted to small time businessmen who were already engaged in a similar enterprise (like computer center/ internet cafe). This decision resulted in the infomediaries using the project equipment for personal business purpose. Lastly, much of the information posted on the site was "routine" and hence, not of much use to the farmers. The portal also has a facility for sending farmers' queries to experts to address specific farm problems. This can be done via an exclusive email account that could be accessed only by the Sanchalak. The farmer can request the sanchalak to send his/ her query to an expert after paying a fixed price. $\mathrm{He} /$ she can view the reply by approaching the Sanchalak a second time and payment of the requisite fee. It was found that the response rate was very slow and reply was usually received after 7-10 days. In the intermittent period, the farmer would visit the Soochna Kutir two/ three times hoping for a reply. Every time he approached the Sanchalak to check for the reply (which can be done only by logging into the system), he had to pay the required fee, thereby losing money. On an average, farmer incurred an expenditure of Rs 5o/- (approximately 1US \$) per query.

IFFCO Airtel Green Card: IFFCO is primarily a fertilizer producing unit, but also provides other agricultural services like crop insurance, agricultural extension, soil testing facilities, etc., to the farmers. IFFCO Kisan Sanchar Limited (IKSL) was incorporated in April, 2007 as a joint venture (JV) company between Indian Farmers Fertilizer Cooperative Limited (IFFCO) and Bharti Airtel in which IFFCO has 50\% stake and Bharti Airtel and Star Global have 25\% equity each. Bharti Airtel Limited is a part of Bharti enterprises and is one of India's leading integrated telecom service provider. The joint venture company offers "IFFCO Airtel Green Card". Under this scheme, affordable mobile handsets are bundled with Airtel mobile connection. The cost of the hand set, Airtel connection with one year validity and IKSL services was Rupees One Thousand (Rs 1000/- or approximately 20 US\$). In addition, farmers 
could call others farmers subscribing to the service at cheaper call rates (@ fifty paisa per minute). All the farmers having IFFCO Airtel Green Card have access to a unique VAS platform that sends five free voice messages related to agriculture (market prices, farming techniques, weather forecasts, dairy farming, animal husbandry, rural health initiatives and fertilizer availability, etc.) every day. But, if the farmer wants to listen to the information a second time, (s)he had to pay the call charge (@ one rupee per minute). In addition, the farmer can also call a dedicated helpline (Helpline number- 534351), manned by experts to seek answers to specific queries. These calls were also charged at the rate of one rupee per minute.

Majority of the farmers felt that the information delivered by IKSL was useful. However, usefulness was interpreted in different ways by farmers belonging to different socio-economic categories. Farmers with high socio-economic status said that the service acted as a reminder for timely agricultural operations. Further, messages about likely pest/insect infestation helped them to take precautionary measures and save their crop from potential loss. On the other hand, farmers belonging to medium and low socio economic status found the service useful as they received relevant agricultural information at their doorsteps. This saved their time and cost (required for travelling to extension agency). However, none of the farmers made proactive use of the service, i.e. they have never used the helpline service.

\section{$5 \quad$ Applying Design Principles and ICTD Initiatives}

How far do these projects incorporate design principles characteristic of enduring CPRs?

Clearly Defined Boundaries: Ostrom (1990) argues that well defined boundaries apply both to the resource system and authorised users. In case of both these initiatives, boundaries of the resource system are well defined. Quantum, nature, types and form of information (though not the actual content) was predetermined. The technology through which information was made available to users has also remained unchanged during the period. On the other hand, users were amorphous due to operational and financial reasons. In case of Janadhar, due to economic factors, informediaries encouraged the youth (50\% users were students) to use Rural Information Centres (RIC) for internet browsing, playing games, academic work, etc. At the same time, primary or authorised users were pushed into the background due to apathy of the infomediary, lack of relevant content, cost related issues, etc. On the other hand, IFFCO Airtel Green Card offered handset, connection and information services at a subsidized rate. In order to take advantage of the subsidy, many non-farmers subscribed to the scheme and used reduced call rates to maintain social networks (for making calls to friends, relatives, etc.) and their developmental use was only incidental and limited. This point is borne out by the fact that only $31.43 \%$ respondents were primarily engaged in agriculture. Authorised users were also few due to logistical issues (non-availability of inputs suggested by the experts in local market) and use of highly technical terms in voice messages. 


\section{Congruence between Appropriation and Provision Rules and Local Conditions:}

This implies a restriction on the number of authorized users and making rules regarding harvesting pattern, how much, when and how a resource can be harvested. This is essential for resource conservation. "How much" is not relevant in this case, as "extraction" of information through digital technologies does not deplete/ limit its availability to others. Similarly, "how" information can be accessed is also clear cut in these two cases (through a databank and expert system that can be accessed only with the permission of the infomediary in first case and using mobile telephony in the second case). "When" in case of Janadhar was problematic as information could be accessed only at the convenience of the infomediary (timings of the Centre were dependent upon the Sanchalak convenience), expert (when he/she is able to respond to the farmers' query), infrastructure (electricity connection, seating capacity, etc.). Further, in both the cases, there were no rules concerning who would be the primary users (which appears to be a more appropriate term when compared to authorized users). While the initiatives themselves were aimed at rural people/farmers for developmental purpose, there was no mechanism to ensure use by them. Hence, users were predominantly students in first case and non-farmers in the second case. In a way, both initiatives highlight "underprovision" of the resource to primary users instead of utilizing the excess capacity for providing the resource to subsidiary users.

Collective Choice Arrangements and Monitoring: Peoples' participation in framing rules that govern the day-to-day operation of the resource is essential as they can be tailored to local and resource conditions in a dynamic environment. Peoples' participation was the leitmotif in development theory and practice during the 1980s. This concept extended to communication projects as can be made out from terms like participatory communication, participatory message design, participatory evaluation, etc. It seems ironic that ICT based development projects that aim to democratize communication process and seek to use information as the prime mover of development have little to contribute in terms of peoples' involvement. Most of them are top down and view citizens as consumers of expert information. External enforcement has largely failed in case of conventional development projects and similar outcomes have been observed in case of several ICT initiatives. In the cases cited above, all decisions regarding technology, content, mode of delivery, operational procedures, etc were taken by "experts" leading to a mismatch between peoples' needs and project outputs at several levels. Peoples' involvement in monitoring and evaluation is considered most mature and highest level of participation. In the absence of sense of ownership, there was no involvement of the people to take/ enforce corrective measures when resource (information) was not provided/ underprovided and the resource system itself was not working efficiently or was highjacked by others.

Graduated Sanctions: Ideally, sanctions against those who break the rules should be developed by the users themselves through consensus. This requires monitoring of resource use by authorized users in the first place and the sanctions themselves should vary with the nature and extent of violation of rules. In case of traditional CPRs, graduated sanctions often take the form of payment in cash or kind coupled with loss of prestige or social disgrace. Is there a violator in these cases? If so, who are they? The studies present an interesting situation as the violators are not the authorized 
users themselves. Use of RIC by youth and neglect of farming community was a consequence of the infomediary's actions (need to make a success of the enterprise) and provisions within the project (which do not stipulate use by farmers, decision to use a business model which incentivizes use of the Centres by others, etc.). In case of IFFCO Airtel Green Card, violators include authorized users (who subscribed to the subsidized connection and passed it on to others due to low cost) and disbursement agency (which allowed ownership by subsidiary users). Sanctions can also be developed by officials, which may be necessary if the user group is not powerful or is unable to come to a consensus regarding sanctions. In these cases, that was clearly absent due to discrepancies at the implementation stage.

Conflict Resolution Mechanisms: All joint use arrangements face disputes at some point in time or the other. Hence, it is vital that the users and officials have access to low cost conflict resolution venues and mechanisms. In its absence, some users may be tempted to free ride or outsiders may appropriate the resource. In many CPR studies it was found that the conflict resolution mechanism is localized and informal with elders/ leaders acting as the arbitrator. However, "the presence of conflict resolution mechanisms does not guarantee that appropriators are able to maintain enduring institutions" (Ostrom, 1994). Conflict is expressed struggle between competing positions held by individuals or groups. It is pertinent to note that, absence of conflict does not always indicate harmony. Often the underrepresented or less powerful individual or group may withdraw. While the farmers in these cases cannot be labelled a less powerful, they were underrepresented/ unrepresented at planning, implementation and evaluation stages. This partially explains underuse of the facility by them rather than expressing discontent.

Minimal Recognition of Rights to Organize: For effective functioning of CPR institutions, it is essential that the authorised users have a right to devise their own institution and that such rights are not challenged by external authorities. When external authorities presume that only they have the authority to make rules, then it is difficult for local users to sustain the "commons" over long run. In the context of natural CPRs, Ostrom (1994) notes that once "the economic and social base has been weakened enough, then simply assigning a local authority to make rules related to the use of common-pool resources would probably not be a sufficient way out of a major dilemma." Decision making, including the best way of disseminating information to farmers through ICT, was centralized in both the cases. Even informediaries (in case of Janadhar) had no say in the payments charged for the services. If they were free to decide on charges on a case to case basis, the infomediaries may not have charged the farmer (when no reply was received from the expert) or the farmer may have negotiated the price. IFFCO Airtel Green Card is operational in most states in India. Pricing, content, mode of implementation is the same across the country. This centralized structure gives rise to problems surrounding cost and content. What may be considered a reasonable cost in an agricultural advanced state like Punjab may not be viewed as such by farmers in Uttarakahnd. Even within the state, farmers from low economic strata felt that the service was expensive. But the scheme has no provision for differential pricing. Also, most of the information delivered to the farmers centred 
on crops grown in the plains (cereals, pulses, etc.). Hence, farmers from the hilly region of the state did not find the information useful as they were mainly engaged in cultivation of horticultural crops.

\section{Discussion}

To date, myriad guidelines and criteria have been used for analysis and evaluation of ICTD projects. They mostly include supply side parameters like access, ICT infrastructure, presence of supportive environment, etc. Demand side issues have received less attention but include assessing the actual benefits accrued to the community. This approach has been extended to study the long term impact of ICT projects by Madon (2004) using Sen's capabilities approach. It has been argued that "there is a need to measure what people in practice can or cannot do with a range of ICT applications that are available and benefits they do or do not derive."

Applying CPR design principles to ICT projects is one way of explaining why people may not be able to use ICT based applications or derive benefits from them. In the present analysis, it was found that the intended users were marginalised due to financial considerations and unrestricted access to other users. This dilemma was compounded by restrictions on use by farmers due to logistical and infrastructure bottlenecks and absence of corrective mechanism. Lack of user participation led to dumping of content that did not address farmers' needs and apathy towards the project.

Users' or community participation in development efforts including ICTD projects have been strongly advocated as it instils a sense of ownership, reflects peoples' needs and incorporates their knowledge. Participation, however, is a tricky concept. In conventional development literature, the concept has been challenged on grounds of lack of resources and skills on part of the people, ideological fuzziness, and problems during actualization. These considerations are equally valid for ICTD projects. One possible way out can be to use existing farmers' groups/ organizations as intermediaries/ representatives in a partnership approach. The conventional Public-Private Partnership model can be modified to involve a technology provider and farmers' organizations or a tri partite arrangement between technology provider, public extension system and farmers' groups. At present, these groups are engaged in input supply, training, networking, marketing, etc. and are attuned to the real needs of the farming community. Involvement of farmers' groups in itself will not ensure total community "participation", but will only lead to greater acceptance of the project resulting in active contribution towards content and operations. At the policy level, the Eleventh Five Year Plan, Government of India stipulates that at least $10 \%$ of the funds allocated for extension activities should be channelized through private agencies, making it feasible to involve farmers' groups.

\section{Concluding Remarks}

Institutions are dynamic structures whose survival and longevity depends upon their ability to adapt to a changing environment. Strong institutions are essential for long 
term sustainability and scalability of ICT projects. All long enduring Common Pool Resources (CPRs) are governed by robust institutions that change with time and need. Application of design principles vary widely across CPRs and as Ostrom points out, sustainability of the resource and governing institutions cannot be explained by the presence or absence of a particular design principle. The fact that they "....do differ partly explains the sustainability of these systems. By differing, the rules take into account specific attributes of the physical systems, cultural views of the world, and the economic and political relationships that exist in the setting".

It would be erroneous to imply that the less than optimal performance of the ICT based projects discussed in this paper is due to the absence of a particular design principle. But, as pointed out during the analysis, the projects seem to be falling short on many design principles deemed essential for strong CPR institutions. It would be fair to admit that the application of CPR design principles to ICT base projects is neither easy nor clear cut. It is complicated by several stakeholders, absence of clear cut "authorised owners", technology related issues and multiple property regimes.

Lastly, the whole discussion hinges on the assumption that information is considered as a resource by the farmers. This supposition may not be true for all farmers. Information is a resource only if it can be converted into a benefit or fulfils a particular need. Agriculture in India (especially Uttarakhand) is limited by several factors like pricing policy, infrastructure, inputs, etc. In such a scenario, farmers are rarely motivated to contest for more and better information. Information is just one component of the system that can make agriculture profitable and farmers seem to realize this better than development agencies with "good intentions".

\section{References}

Barala, P.: A Study of Rural Knowledge Centers in Nainital District of Uttaranchal. Unpublished M.Sc. Thesis, Department of Agricultural Communication, GBPUAT, Pantnagar (2006)

Benkler, Y.: Coase's Penguin, or Linux and the nature of the firm. Yale Law Journal 112, 369-446 (2002)

Bernbom, G.: Analyzing the Internet as a Common Pool Resource: The Problem of Network Congestion. In: Eighth Biennial Conference of the International Association for the Study of Common Property, Bloomington, Indiana (2000)

De Moor, T.: From common pastures to global commons. An historical perspective on interdisciplinary approaches to commons. In: Thirteenth Biennial Conference of the International Association for the Study of Common Property, Hyderabad, India (2011)

Hess, C.: Is There Anything New Under the Sun? A Discussion and Survey of Studies on New Commons and the Internet. In: Eighth Biennial Conference of the Interna-tional Association for the Study of Common Property, Bloomington, Indiana (2000)

Hess, C., Ostrom, E.: Ideas, Artifacts, and Facilities: Information as a Common-Pool-Resource. Law and Contemporary Problems 66 (2003)

Hess, C., Ostrom, E.: Ideas, artifacts and facilities: Information as a Common Pool Resource, http: / / www. law. duke. edu / journals / 66LCPHess

Hofmokl, J.: The Internet commons: towards an eclectic theoretical framework. International Journal of the Commons 4, 1 (2010) 
Kiri, K., Menon, D.: For Profit Rural Kiosks in India: Achievements and Chal-lenges, http: / /www.i4donline. net/articles/currentrticle.asp?articleid=700\&typ=Features

Machlup, F.: The Economics of Information: A New Classification. InterMedia 11, 2 (1983)

Madon, S.: Evaluating the developmental impact of e-governance initiatives: An ex-ploratory framework". The Electronic Journal of Information Systems in Developing Countries 5, 113 (2004)

Oakerson, R.J.: Analyzing the Commons: A Framework. In: Bromley, D. (ed.) Making the Commons Work: Theory, Practice and Policy. ICS Press, San Francisco (1992)

Ostrom, E.: Governing the Commons: The Evolution of Institutions for Collective Action. Cambridge University Press, Cambridge (1990)

Ostrom, E.: Neither market nor state: Governance of Common Property Resources in Twenty First Century. IFPRI Lecture Series (2) (1994)

Sahota, C.: Use of Mobile Phones in Agricultural Extension: A Study in Uttarakhand. Unpublished M.Sc. Thesis, Department of Agricultural Communication, GBPUAT, Pantnagar (2009)

Toyama, K.: Can Technology End Poverty?, http: / / www. bostonreview. net/BR35.6/toyama.php

Veeraraghavan, R., Singh, G., Toyama, K., Menon, D.: Kiosk Usage Measure-ment Using a Software Logging Tool, http://research.microsoft.com/en-us/um/india/ projects/kiosktool/rajesh_vibelog_berkeley.pdf

Yunus, M.: Foreword. In: Digital Review of Asia Pacific 2007-2008. Sage, New Delhi (2006) 